\title{
Inovasi Pembelajaran Bahasa Arab Daring di Masa Pandemi Covid-19
}

\author{
Andi Putra ${ }^{1]}$, Rita Gamasari ${ }^{2]}$, Novebri ${ }^{3]}$ \\ ${ }^{1}$ Sekolah Tinggi Teknologi Payakumbuh \\ ${ }^{2,3}$ Sekolah Tinggi Agama Islam Negeri Mandailing Natal \\ E-mail: ${ }^{1]}$ drandiputra@gmail.com \\ ${ }^{2]}$ ritagamasari@stain-madina.ac.id, \\ ${ }^{3]}$ novebri@stain-madina.ac.id
}

\begin{abstract}
Abstrak
Sebelum pandemi Covid-19 melanda dunia pendidikan, pembelajaran bahasa Arab dipastikan hampir tidak mengalami kendala dalam pembelajaran tatap muka. Empat kemahiran berbahasa yang menjadi tujuan utama pembelajaran bahasa Arab, yaitu maharoh istima', kalam, qira'ah dan kitabah, dapat diterapkan dalam perkuliahan tatap muka. Permasalahan kemudian muncul manakala situasi pandemi mewajibkan perkuliahan secara daring. Dosen berupaya mencari inovasi untuk beradaptasi dengan pembelajaran online agar tujuan pembelajaran tetap tercapai dengan baik. Tujuan penelitian ini adalah menggambarkan inovasi pembelajaran bahasa Arab secara daring pada masa pandemi Covid-19 yang diselenggarakan di Sekolah Tinggi Agama Islam (STAIN) Mandailing Natal Provinsi Sumatera Utara sebagai upaya menekan mata rantai penyebaran Covid-19 di lingkungan perguruan tinggi. Jenis penelitian yang digunakan adalah penelitian kualitatif, teknik survey dilakukan kepada mahasiswa menggunakan google form yang diisi setelah dibagikan melalui pesan WhatsApp. Subjek penelitian adalah mahasiswa STAIN Mandailing Natal pada semester II dan telah lulus mata kuliah bahasa Arab pada semester I. Analisis data menggunakan teknik analisis interaktif Miles \& Huberman. Hasil penelitian menunjukkan bahwa: (1) Inovasi pembelajaran daring mata kuliah Bahasa Arab diaplikasikan melalui aplikasi Whatsap, G-mail, Zoom, Google Meet, dan Siakad yang dapat diakses mahasiswa. (2) Pembelajaran daring efektif menarik minat mahasiswa karena dosen mampu mengkombinasikan dengan metode yang bervariasi, baik melalui file pdf, video pembelajaran, link Youtube, Animasi, atau rekam layar. Sehingga dapat disimpulkan bahwa pembelajaran bahasa Arab daring di STAIN Mandailing Natal pada masa Covid-19 memberi ruang inovasi bagi dosen dan mahasiswa sehingga tujuan pembelajaran bahasa Arab tercapai seperti yang diharapkan.
\end{abstract}

Kata kunci: Pembelajaran bahasa Arab daring, Covid-19, google form

\section{Arabic Learning Innovation Online In Pandemic Covid-19}

\begin{abstract}
Before the Covid-19 pandemic hit the world of education, it was certain that Arabic learning had almost no obstacles in face-to-face learning. The four language skills which are the main objectives of learning Arabic, namely maharoh istima', kalam, qira'ah and kitabah, can be applied in face-to-face lectures. Problems then arise when the pandemic situation requires online lectures. Lecturers are trying to find innovations to adapt to online learning so that learning objectives can still be achieved properly. The purpose of this study is to describe the innovation of learning Arabic online during the Covid-19
\end{abstract}


pandemic which was held at STAIN Mandailing Natal as an effort to suppress the chain of spread of Covid-19 in the university environment. The type of research used is qualitative research, survey techniques are carried out to students using a google form that is filled out after being distributed via WhatsApp messages. The research subjects were students of the Islamic High School (STAIN) Mandailing Natal Province of North Sumatra in the second semester and had passed the Arabic language course in first semester. Data analysis was carried out using the Miles \& Huberman interactive analysis technique. The results of the study show that: (1) The innovation of online learning for Arabic courses is applied through WhatsApp, G-mail, Zoom, Google Meet, and Siakad applications that can be accessed by students. (2) online learning innovations are effective in attracting students' interest because lecturers are able to combine various methods, either through pdf files, learning videos, Youtube links, animations, or screen recordings. So that be concluded that learning Arabic online at STAIN Mandailing Natal in pandemic Covid-19 an innovation space for lecturers and students so that the objectives of learning Arabic were achieved as expected.

Keywords: Online arabic learning, Covid-19, google form

\section{PENDAHULUAN}

Pandemi Covid-19 tidak hanya membawa perubahan secara global pada negara kita, tetapi juga mempengaruhi proses pembelajaran di sekolah dan perguruan tinggi. Pandemi ini telah melanda 215 negara di dunia, memberikan tantangan tersendiri bagi lembaga pendidikan, khususnya Perguruan Tinggi. Untuk melawan Covid-19, Pemerintah telah melarang untuk berkerumun. Kebiasaan baru dengan memakai masker dan selalu cuci tangan, pembatasan sosial (social distancing) dan menjaga jarak fisik (physical distancing). Berdasarkan Surat Edaran Kemendikbud Dikti No. 4 tahun 2020, Kementerian Pendidikan dan Kebudayaan untuk sementara waktu akhirnya tidak mengizinkan perguruan tinggi untuk melaksanakan perkuliahan tatap muka, sebaliknya memerintahkan untuk melaksanakan perkuliahan atau pembelajaran secara daring. Untuk mengurangi konsekuensi yang berpotensi menghancurkan dari pandemi Covid-19, pemerintah dan pemangku kepentingan didorong untuk mengambil tanggapan kebijakan (De Giusti, 2020), sehingga pengaturan jam kerja, sosialisasi dan akademik kampuspun berubah setelah diterapkannya lockdown (Lianawati, 2022). Dengan itu perguruan tinggi diminta untuk dapat melaksanakan perkuliahan atau pembelajaran secara daring atau online (Firman \& Rahman, 2020). Di masa puncak pandemi, hampir seluruh perguruan tinggi melaksanakan perkuliahan daring. Bukan hanya perguruan tinggi negeri, tetapi juga perguruan tinggi swasta di bawah koordinasi lembaga layanan pendidikan tinggi (LLDIKTI). Sampai saat ini, sudah puluhan perguruan tinggi negeri dan swasta di Indonesia yang melaksanakan kuliah online atau pembelajaran daring (Susanty, 2020). Terdapat sekitar 65 perguruan tinggi di Indonesia yang telah memberlakukan pembelajaran daring dalam mengantisipasi penyebaran Covid-19 (CNNIndonesia, 2020).

Dalam rangka pencegahan
penyebaran Covid-19, WHO
mengumumkan untuk menghentikan
kegiatan-kegiatan yang mengumpulkan
orang banyak yang dapat menyebabkan


kerumunan massa. Oleh sebab itu, pembelajaran tatap muka di kelas yang mengumpulkan dosen dan mahasiswa untuk dapat dikaji kembali pelaksanaannya. Perkuliahan tentunya harus tetap berjalan dengan ketentuan harus mampu mencegah kontak secara fisik antara sesama mahasiswa juga dengan dosennya (Sadikin \& Hamidah, 2020). Wabah Covid-19 bukanlah suatu hal yang mampu menghentikan jalannya proses pendidikan. Meskipun covid 19 mengharuskan untuk melakukan isolasi ruang gerak sehingga dalam menjalankan fungsi dan tugas pengajaran menyebabkan bekerja dari rumah (work from home), tetapi covid 19 tidak menjadi penghalang bagi para pendidik untuk berinovasi (Bulan \& Zainiyati, 2020). Selama ini faktanya memang masih banyak diantara dosen dan mahasiswa yang enggan menggunakan teknologi yang telah dimiliki, baik oleh kampus ataupun mahasiswa dalam melakukan proses pembelajaran. Padahal salah satu yang berperan penting dalam menyukseskan pembelajaran di kelas adalah media belajar berbasis teknologi. (Khusniyah \& Hakim, 2019). Pemanfaatan Teknologi Informasi dalam dunia pendidikan dapat menjadi pendorong lembaga tersebut menjadi bersifat ekstrovert yang lebih proaktif, meninggalkan sifat yang sebelumnya introvert universitas (conventional university) (Azzuhri, 2009).

Bentuk pembelajaran yang dapat dijadikan solusi pada masa pandemi Covid-19 adalah pembelajaran daring. Pembelajaran daring adalah pembelajaran yang bisa mempertemukan dosen dengan mahasiswa untuk tetap dapat melaksanakan interaksi pembelajaran dengan bantuan media internet (Kuntarto, 2017). Pembelajaran daring memiliki tantangan, solusi dan hambatan tersendiri yang merupakan aspek penting yang harus diselesaikan (D. Jamaluddin, T. Ratnasih, 2020). Mahasiswa dapat belajar kapan dan di mana saja, sehingga mengembangkan keterampilan baru dalam proses yang mengarah pada pembelajaran (Dhawan, 2020). Kemendikbud telah bergabung dengan tujuh online platform pembelajaran yaitu Google Indonesia, Sekolahmu, Smart Classes, Quipper, Zenius, dan Microsoft. Setiap platform akan menyediakan fasilitas yang dapat diakses publik dan gratis. (Abidah et al., 2020). Perangkat mobile beserta internet seperti smartphone atau telepon adroid, laptop, komputer PC, tablet, dan iphone yang dapat dipergunakan untuk mengakses informasi kapan saja dan dimana saja (Sadikin \& Hamidah, 2020). Perguruan tinggi perlu memperhatikan keberlangsungan kuliah daring penerapan mobile learning (Darmalaksana, 2020). Salah satu alat komunikasi yang paling banyak dipakai oleh mahasiswa dalam proses pembelajaran daring adalah Smart phone (Pendy et al., 2022).

Pembelajaran daring merupakan pembelajaran yang memanfaatkan teknologi, salah satunya media internet untuk menyampaikan atau mendapatkan materi pembelajaran dengan lebih fleksibel. (Astuti \& Febrian, 2019). Pembelajaran daring dapat menghubungkan peserta didik dengan sumber belajarnya (database, pakar/instruktur, perpustakaan) yang secara fisik terpisah bahkan berjauhan namun dapat saling berkomunikasi, berinteraksi atau berkolaborasi (secara langsung/ synchronous dan secara tidak langsung/asynchronous).

Inovasi dalam pembelajaran daring merupakan sebuah kemestian bagi dosen dan tenaga pengajar. Pada kenyataannya, pembelajaran daring perlu didesain lagi oleh tenaga pengajar 
agar dapat memaksimalkan fungsinya. Terlebih untuk memenuhi kebutuhan peserta didik. Peserta didik terutama mahasiswa milenial yang sudah terpapar digital sejak lahir tentu sangat mudah beradaptasi dengan pembelajaran berbasis teknologi ini (Susanty, 2020). Oleh sebab itu dituntut kesigapan dosen untuk berinovasi dan beradaptasi dengan pembelajaran berbasis teknologi, menguasai penggunaan platform digital kekinian, seperti google form, google meet, zoom meeting, whatsap, google classroom, quiziz, dan lainnya.

Melalui pembelajaran daring yang menggunakan perangkat teknologi seyogianya dosen tetap dapat mengukur efektifitas setiap tugas yang diberikan sehingga hasil pembelajaran berjalan sesuai dengan harapan. Disamping itu, perguruan tinggi dituntut selalu siap melakukan transformasi pembelajaran dalam waktu singkat. Perguruan tinggi dipaksa untuk merevolusi proses pembelajaran ke pemanfaatan teknologi pembelajaran daring. Meskipun sejak awal perguruan tinggi sudah mulai mengenalkan e-learning tetapi faktanya belum semua dosen mengikuti pelatihan e-learning tersebut. Bahkan masih banyak dosen yang gagap teknologi dan gugup menggunakan aplikasi online.

Kolaborasi antara inovasi dan teknologi sangat penting dalam membantu proses pembelajaran. Hal ini semakin terasa di saat pandemi Covid19. Perguruan tinggi harus membuka peluang bagi teknologi untuk berperan lebih luas dalam pembelajaran. Tam dan El Azar sebagaimana dikutip oleh (Susanty, 2020) menyatakan bahwa pandemi Covid-19 dapat menyebabkan tiga perubahan mendasar dalam pendidikan global. Pertama, mengubah cara jutaan orang dididik. Kedua, solusi baru dalam pendidikan yang dapat membawa inovasi baru yang sangat dibutuhkan. Ketiga, dengan adanya kesenjangan digital dapat menyebabkan pergeseran baru dalam pendekatan pendidikan. Dengan demikian, tidak dapat dipungkiri bahwa pandemi Covid19 telah membawa perubahan pada pergeseran paradigma perguruan tinggi terhadap pembelajaran berbasis teknologi.

STAIN Mandailing Natal adalah salah satu kampus yang ikut terdampak Covid-19. Sejak bulan Maret 2019, kampus ini sudah menerapkan sistem pembelajaran daring untuk semua mata kuliah teori. Sebagaimana kampus lainnya, STAIN Mandailing Natal juga menuntut para dosen untuk berinovasi dalam melaksanakan pembelajaran daring. Hal yang cukup mendukung adalah mayoritas dosen di kampus ini masih terbilang dosen milenial yang rata-rata berusia 26-37 tahun. Ini karena usia STAIN Mandailing Natal yang masih 4 tahun setelah dinegerikan pada tahun 2018 dan menerima lebih kurang 120 orang dosen PNS.

Berbagai inovasi dari dosen milenial pada masa Covid-19 mulai diterapkan dalam pembelajaran daring. Demikian juga pada mata kuliah Bahasa Arab. Bahasa Arab merupakan mata kuliah wajib yang harus diambil oleh mahasiswa dari 16 program studi. Tidak hanya prodi keagamaan, tetapi termasuk prodi-prodi umum. Hal ini karena STAIN Mandailing Natal adalah sekolah tinggi agama Islam, dimana seperti kita ketahui al-Qur'an dan hadist nabi adalah pedoman hidup bagi umat Islam (Novebri \& Dewi, 2020) dalam bahasa Arab. Bahasa Arab juga menjadi mata kuliah bersyarat yang harus diikuti oleh mahasiswa semester 1. Setelah lulus bahasa Arab I, maka diizinkan untuk mengambil mata kuliah bahasa Arab II pada semester 2. Bahasa Arab adalah bahasa Al-Qur'an dan Hadist, yang mana keduanya tidak bisa dipisahkan antara satu dengan yang lainnya. Apabila 
mempelajari Al- Qur'an berarti juga mempelajari bahasa Arab. Pemahaman terhadap al-Qur'an sesuai dengan sejauh mana pemahamannya dengan menggunakan pendekatan bahasa Arab (Anah, 2020).

STAIN Mandailing Natal berusaha membekali mahasiswa dengan kemampuan bahasa Arab. Kampus yang baru dinegerikan tanggal 12 April 2018 ini telah memiliki 18 orang dosen PNS bahasa Arab yang home basenya di program studi Pendidikan Bahasa Arab (PBA) dan program studi Bahasa dan sastra Arab (BSA). Meskipun terkendala Covid-19, dosen bahasa arab tetap berupaya berinovasi melaksanakan pembelajaran melalui flatform daring. Kendala yang dihadapi tentu banyak dari segi mahasiswa, baik dari segi ekonomi seperti tidak memiliki android dan biaya pulsa, serta daerah tempat tinggal yang diluar jangkauan signal.

Sebagai kampus baru, STAIN Mandailing Natal masih dalam tahap mengenalkan diri di kabupaten Mandailing Natal dan sekitarnya. Input Mahasiswa yang masuk ke kampus ini mayoritas berasal dari kabupaten Mandailing Natal dan kabupaten sekitarnya. Sejak alih status menjadi kampus negeri, pertambahan mahasiswa baru masih berkisar 500 orang pada tahun akademik 2019/2020.

Penelitian ini mencoba menjawab pertanyaan seputar inovasi pembelajaran bahasa Arab daring di STAIN Mandailing Natal, aplikasi apa saja yang digunakan dalam pembelajaran bahasa Arab daring, bagaimana perkuliahan daring dalam pandangan mahasiswa, bagaimana keaktifan mahasiswa dalam perkuliahan bahasa Arab daring, dan bagaimana konsistensi dosen bahasa Arab dalam melaksanakan perkuliahan daring. Adapun tujuan dari penelitian ini adalah untuk mendapatkan gambaran inovasi pembelajaran bahasa Arab daring di Sekolah Tinggi Agama Islam Negeri (STAIN) Mandailing Natal semasa pandemi Covid-19. Penelitian berkaitan dengan pembelajaran di masa pandemi Covid-19 telah pun banyak dilakukan oleh berbagai peneliti di berbagai tempat. Penelitian itu diantaranya yaitu (Wulandari \& Purwanta, 2020) meneliti di surakarta pada jenjang pendidikan TK; (Putria et al., 2020) (Putria et al., 2020) meneliti di Sukabumi pada jenjang SD (Hamdani \& Priatna, 2020) yang meneliti di Kabupaten Subang pada jenjang SD ; (Anggrawan, 2019); (Firman \& Rahman, 2020) meneliti mahasiswa prodi Biologi (FKIP) Universitas Sulawesi Barat (Unsulbar) (Khusniyah \& Hakim, 2019) meneliti mahasiswa prodi bahasa Inggris pada UIN Mataram (Dinata, 2022) meneliti di Universitas Muhammadiyah Kotabumi. Oleh karena itu penelitian ini dilakukan dalam rangka menambah kelengkapan penelitian di bidang pembelajaran bahasa Arab dan PTKIN.

\section{METODE}

Penelitian ini bersifat penelitian kualitatif Bertujuan untuk memberi gambaran tentang pembelajaran bahasa Arab pada masa Covid-19 secara daring yang diselenggarakan di STAIN Mandailing Natal sebagai upaya dalam memutus mata rantai penyebaran virus Covid-19 pada perguruan tinggi. Pembelajaran bahasa arab daring yang diteliti yakni proses pembelajaran yang menggunakan media yang dapat diakses menggunakan layanan internet, diantaranya seperti: whatsapp, zoom meeting, google classroom, dan lain sebagainya. Teknik survey dilakukan dalam proses pengumpulan informasi dari sejumlah responden tentang suatu isu dan topik tertentu (Gunawan, 2017). Penelitian dilakukan dengan terlebih dahulu mengadakan survey kepada 
mahasiswa mengenai penerapan pembelajaran daring. Survey disebarkan menggunakan google form yang diberikan kepada mahasiswa melalui pesan WhatsApp. Google Form merupakan salah satu komponen layanan Google Docs. Aplikasi ini sangat cocok untuk mahasiswa, guru, dosen, pegawai kantor dan professional yang senang membuat quiz, form dan survey online. (Batubara, 2016). (Bulan \& Zainiyati, 2020). Ada 171 orang subyek yang telah memberikan respon terhadap survei yang disebarkan. Hasil survey kemudian dikelompokkan ke dalam tiga kategori respon mahasiswa: (1) Setuju dengan penerapan pembelajaran daring; (2) Tidak setuju dengan penerapan pembelajaran daring; (3) Ragu dengan pelaksanaan pembelajaran daring.

Komponen yang terdapat dalam kuesioner terdiri atas 5 bagian. Bagian 1 berupa isian, yaitu pertanyaan tentang informasi nama, jenis kelamin, dan asal prodi. Bagian 2 adalah pilihan, yaitu pertanyaan tentang aplikasi yang digunakan dalam pembelajaran bahasa Arab daring. Bagian 3 adalah pilihan terdiri dari 15 pertanyaan seputar kondisi pembelajaran bahasa Arab daring. Bagian 4 adalah pilihan, yaitu pertanyaan tentang metode pembelajaran daring. Bagian 5 adalah essay tentang pendapat mengenai pembelajaran bahasa Arab secara daring saat terjadi pandemi Covid-19. Subjek penelitian adalah mahasiswa semester II yang mengambil mata kuliah bahasa Arab di STAIN Mandailing Natal yang telah melakukan pembelajaran bahasa Arab secara daring, dan dikelompokkan berdasarkan respon dari subjek penelitian. Analisis data penelitian yang dilakukan menggunakan model analisis Miles \& Huberman (1994) yang terdiri dari tiga tahapan, yaitu reduksi data, display data, serta penarikan dan verifikasi kesimpulan, dapat dilihat pada Gambar 1.

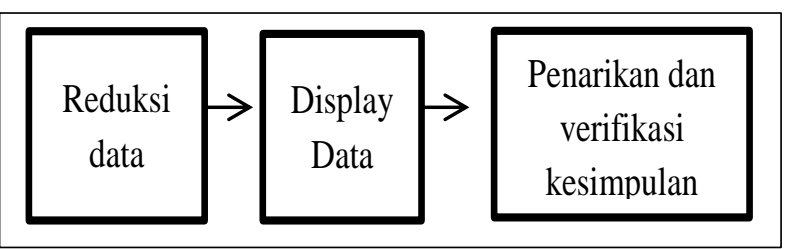

Gambar 1. Model analisis Miles \& Huberman (1994)

Model analisis data penelitian pada tahap reduksi data yaitu tahap pengumpulan seluruh informasi yang diperlukan dari hasil wawancara lalu dilakukan pengelompokan datanya. Tahap kedua yaitu display data yang merupakan pemaparan data yang dibutuhkan dalam melakukan penelitian dan yang tidak perlu akan dibuang. Tahap ketiga yaitu penarikan dan verifikasi kesimpulan yaitu tahap interpretasi data penelitian yang akan ditarik untuk membuat kesimpulan berdasarkan fenomena yang didapatkan (Miles, M. B., \& Huberman, M.,1994).

\section{HASIL DAN PEMBAHASAN}

Subjek penelitian ini adalah mahasiswa semester II yang telah lulus mata kuliah bahasa Arab I di STAIN Mandailing Natal yang telah melaksanakan pembelajaran bahasa Arab secara daring pada semester sebelumnya. Setelah melakukan survey maka didapatkan 171 orang subjek penelitian dari beberapa prodi, yaitu: Ekonomi Syariah (ES) sebanyak 22, Bahasa dan Sastra Arab (BSA) 2, Hukum Ekonomi Syariah (HES) 17, Hukum Keluarga Islam (HKI) 2, Ilmu Hadis (IH) 2, Komunikasi Penyiaran Islam (KPI) 3, Manajemen Bisnis Syariah (MBS) 1, Pendidikan Agama Islam (PAI) 30, Manajemen Dakwah (MD) 5, Manajemen Pendidikan Islam (MPI) 45, Pendidikan Bahasa Arab (PBA) 6, Perbankan Syariah (PS) 4, Pendidikan Islam Anak Usia Dini 
(PIAUD) 1, Tadris Bahasa Inggris (TBI) 10, dapat dilihat pada Gambar 2.

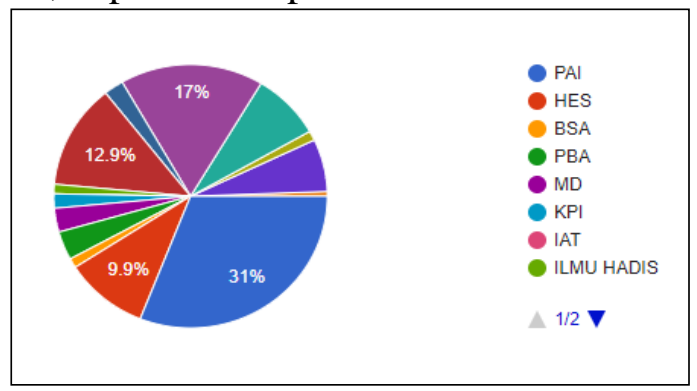

Gambar 2. Responden berdasarkan program studi

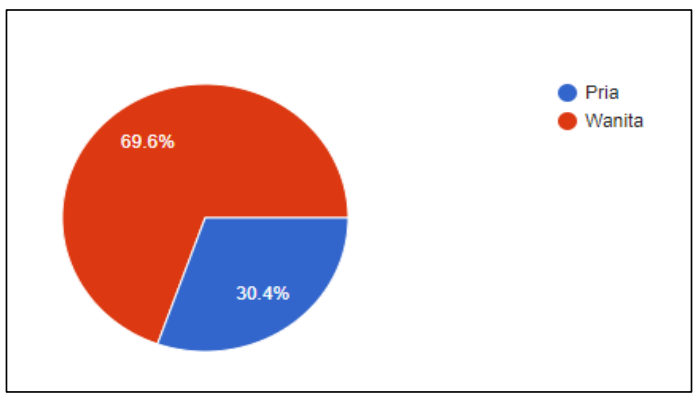

Gambar 3. Responden berdasarkan jenis kelamin

Jika dilihat dari jenis kelaminnya terdiri dari 52 orang mahasiswa berjenis kelamin laki-laki dan 108 orang mahasiswa berjenis kelamin perempuan, dapat dilihat pada gambar 3. Data diperoleh melalui pengisian pertanyaanpertanyaan yang dibagikan kepada seluruh responden dalam bentuk google form. Selanjutnya data yang terkumpul dianalisis untuk dideskripsikan.

\section{a. Media Pembelajaran Bahasa Arab Secara Daring}

Perkuliahan bahasa Arab secara daring dilaksanakan pada semester II (semester genap TA 2019/2020). Aplikasi pembelajaran daring dalam mata kuliah bahasa Arab yang paling banyak digunakan yaitu whatsaap sebanyak 165 responden (96,5\%), google classrom 25 responden $(14,6 \%)$, zoom meeting 6 responden $(3,5 \%)$ seperti yang ditampilkan pada gambar 4 .

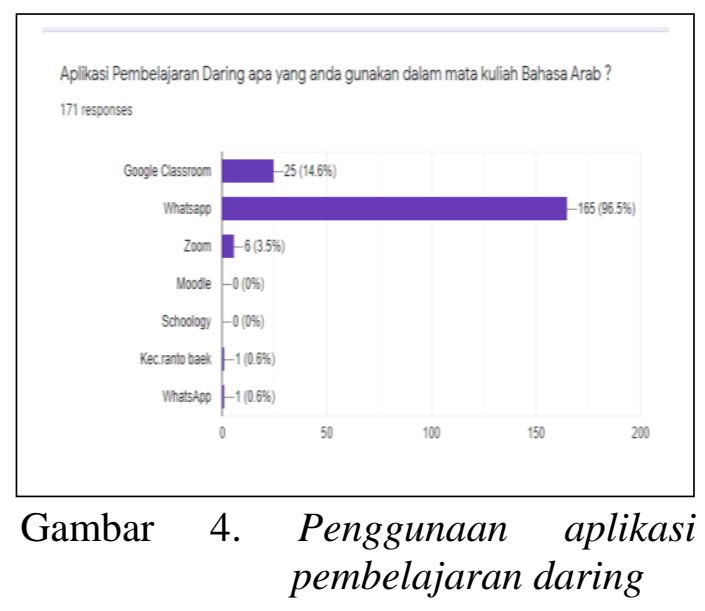

Berdasarkan gambar 4, diketahui bahwa penggunaan aplikasi whatsap sebagai media pembelajaran daring menjadi pilihan terbanyak yang digunakan mahasiswa dan dosen bahasa Arab di STAIN Mandailing Natal. Hanya sebagian kecil saja yang menggunakan aplikasi google classroom dan zoom. Sedangkan aplikasi moodle dan schoology sama sekali belum digunakan dalam pembelajaran. Dalam pembelajaran daring dibutuhkan kreativitas dosen dan mahasiswa untuk memanfaatkan aplikasi-aplikasi online yang tersedia, sehingga proses pembelajaran menjadi lebih menyenangkan dan tidak membosankan meskipun dilaksanakan tanpa tatap muka (Novebri, 2021) dan tentunya ini didukung dengan strategi pembelajaran yang mampu mengaktifkan mahasiswa dalam berdiskusi bersama dosen (Novebri \& Afrizal, 2021).

\section{b. Pembelajaran Daring dalam Perspektif Mahasiswa}

Pembelajaran Bahasa Arab secara daring adalah kebiasaan baru di masa pandemi. Pembelajaran daring di satu sisi membawa kemudahan, namun disisi lain memiliki sejumlah keterbatasan. Gambar 5 menunjukkan bahwa 71 responden menyatakan setuju tentang Belajar Bahasa Arab secara 
daring lebih menyenangkan, 5 responden menjawab sangat setuju, dan 95 orang responden menyatakan tidak setuju jika pembelajaran daring lebih menyenangkan. Artinya, lebih banyak responden yang menyatakan bahwa belajar daring tidak lebih menyenangkan. Mayoritas mahasiswa semester II STAIN Mandailing Natal setuju jika pembelajaran daring sangat fleksibel dan bisa dilakukan kapan dan dimana pun. Gambar 5 menunjukkan bahwa sebanyak 34 responden menyatakan sangat setuju jika pembelajaran daring lebih fleksibel, 113 responden menjawab setuju, dan hanya 24 responden yang menyatakan tidak setuju jika pembelajaran daring lebih fleksibel. Hal ini berarti mayoritas mahasiswa setuju pembelajaran daring lebih fleksibel.

Di satu sisi, pembelajaran daring di masa pandemi dapat mengurangi biaya yang diperlukan mahasiswa untuk mengikuti perkuliahan. Biaya kos dan biaya transportasi harian cukup besar, mengingat lokasi kampus yang lumayan jauh dari pusat kota. Pembiayaan akan jauh berkurang ketika mahasiswa dapat tinggal di rumah orang tua dan tidak perlu biaya transportasi ke kampus. Namun, dalam perspektif mahasiswa STAIN Mandailing Natal, sebanyak 85 responden menyatakan tidak setuju dengan pembelajaran daring biayanya lebih murah. 70 responden menyatakan setuju jika biaya pembelajaran daring lebih murah, dan 15 responden menyatakan sangat setuju jika dengan pembelajaran daring biaya menjadi lebih murah. Hal Ini menunjukkan bahwa sebanyak $50 \%$ responden tidak setuju menyatakan perkuliahan daring biayanya lebih murah. Lokasi tempat tinggal mahasiswa STAIN Mandailing Natal cukup bervariasi. Mahasiswa berasal dari berbagai kecamatan di Mandailing Natal, ada juga dari luar kabupaten Mandailing Natal, seperti kabupaten Tapanuli Tengah, Sibolga, Labuhan Batu, Padang Lawas, dan Sibuhuan. Kondisi tempat tinggal juga mempengaruhi akses internet. Berdasarkan hasil pada gambar 5 dijelaskan bahwa sebanyak 107 responden menyatakan tidak memiliki akses internet yang lancar. 58 responden menyatakan memiliki akses yang lancar, dan hanya 6 responden yang memiliki akses internet sangat lancar. Hal ini berarti mayoritas mahasiswa tidak memiliki akses internet yang bagus di daerah tempat tinggalnya masingmasing.

Perkuliahan daring menuntut mahasiswa untuk mahir mengunakan berbagai aplikasi pembelajaran di smartpone. Sebanyak 112 responden mampu menggunakan aplikasi belajar daring dengan baik. 8 responden sangat mampu untuk menggunakan aplikasi belajar daring, sedangkan 41 responden menyatakan tidak mampu menggunakan aplikasi belajar daring dengan baik. Ini berarti bahwa sebahagian besar mahasiswa STAIN Mandailing Natal mampu menggunakan aplikasi belajar daring dengan baik. Dalam pembelajaran daring, penggunaan internet sangat penting sebagai sumber informasi. Sebanyak 126 responden juga setuju menyatakan bahwa referensi dari internet sangat membantu untuk perkuliahan daring. 22 responden sangat setuju. Namun, ada 23 responden menyatakan tidak setuju jika referensi internet membantu perkuliahan daring. Artinya, sebahagian besar setuju dengan menjadikan internet sebagai sumber informasi dalam perkuliahan. Adapun perspektif mahasiswa tentang ujian daring, baik ujian tengah semester (UTS) maupun ujian akhir semester (UAS), menurut 18 responden menyatakan sangat setuju bahwa kecemasan dalam menghadapi UTS/UAS secara daring 
berkurang, sebanyak 98 responden juga setuju kalau kecemasan berkurang jika ujian dilakukan secara daring. Adapun yang tidak setuju dengan pernyataan tersebut sebanyak 55 responden. Artinya, sebahagian besar mahasiswa sepakat menyatakan bahwa ujian daring dapat mengurangi tingkat kecemasan dalam ujian.

\section{c. Keaktifan Mahasiswa dalam Mengikuti Pembelajaran Bahasa Arab Daring}

Perkuliahan daring pada masa pandemi semestinya tidak mengurangi semangat dan motivasi mahasiswa dalam belajar bahasa Arab. Adapun kehadiran dalam pembelajaran bahasa Arab daring berdasarkan gambar 5 bahwa sebanyak 101 responden menyatakan selalu hadir dalam perkuliahan bahasa Arab, 61 responden menjawab sangat setuju selalu hadir, dan hanya 9 responden yang tidak setuju untuk selalu hadir dalam pembelajaran bahasa Arab daring. Hal ini menunjukkan bahwa kehadiran dalam pembelajaran bahasa Arab sangat bagus, dan hanya sebagian kecil saja yang menjawab tidak setuju untuk selalu hadir.

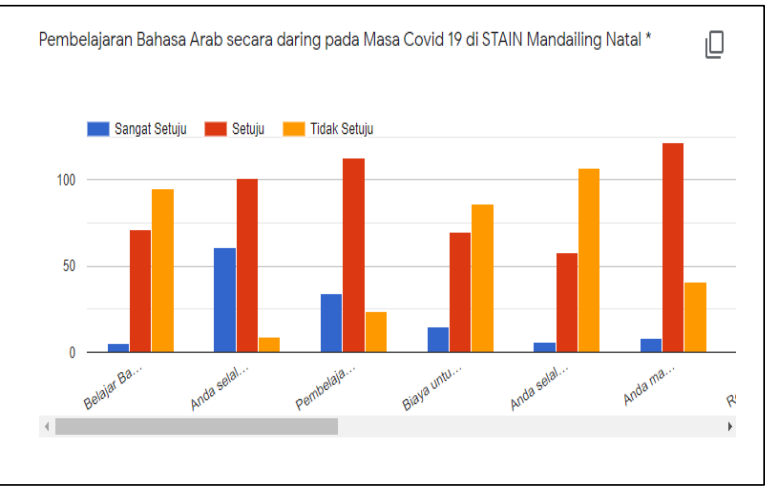

Gambar 5. Partisipasi mahasiswa dalam pembelajaran bahasa Arab
Dilihat dari semangat dan antusiasme mahasiswa mengikuti perkuliahan bahasa Arab daring sebanyak 101 responden bersemangat mengikuti perkuliahan daring, 15 responden sangat antusias dan bersemangat, sedangkan 55 responden lainnya tidak merasa bersemangat dalam pembelajaran daring bahasa Arab di STAIN Mandailing Natal.

Dapat dipahami bahwa kondisi mahasiswa dalam mengikuti pembelajaran tidak sama antara satu dengan yang lain. Semangat mengikuti perkuliahan berpengaruh untuk mendorong keaktifan dalam kelas virtual Beberapa mahasiswa mampu aktif dan berani bertanya kepada dosen terkait materi yang kurang difahami. Namun, sebagian mahasiswa lainnya masih malu dan enggan untuk bertanya. Berdasarkan hasil gambaran yang diperoleh dari Gambar 6 diketahui bahwa sebanyak 89 responden menyatakan bahwa pembelajaran daring membangkitkan keberanian untuk bertanya kepada dosen dibanding dengan perkuliahan tatap muka. Sebanyak 31 responden menjawab sangat setuju dengan pernyataan tersebut. Sedangkan 51 responden lainnya menyatakan bahwa pembelajaran daring tidak membangkitkan keberanian untuk bertanya kepada dosen. Artinya, sebagian besar mahasiswa lebih berani bertanya kepada dosen dalam pembelajaran daring dibanding pembelajaran tatap muka.

Keaktifan mahasiswa juga dapat dinilai berdasarkan ketepatan waktu pada pengumpulan tugas. Dari data yang diperoleh menunjukkan bahwa sebanyak 95 responden menyatakan tepat waktu mengumpul tugas, 33 responden sangat setuju mengumpul tugas tepat waktu dalam pembelajaran daring, dan 43 responden tidak setuju mengumpul tugas tepat waktu. Artinya, lebih banyak 
mahasiswa yang aktif dan tepat waktu mengumpul tugas dibanding mahasiswa yang tidak tepat waktu mengumpul tugasnya. Pada dasarnya, kelas virtual sama dengan kelas tatap muka. Peraturan dalam ruang kelas tatap muka juga sama dengan peraturan pembelajaran daring. Misalnya, masuk tepat waktu, aktif dalam kelas, tepat waktu mengumpul tugas, dan lainnya. Peraturan perkuliahan sebaiknya tetap terlaksana dengan baik meskipun dalam ranah kelas virtual. Adapun dalam pembelajaran daring bahasa Arab, sebanyak 95 responden menyatakan mampu menaati aturan perkuliahan daring, 33 responden menyatakan sangat mampu, dan 43 responden menyatakan tidak mampu mengikuti aturan perkuliahan dengan baik. Hal ini berarti sebahagian besar mahasiswa mampu menjalankan aturan perkuliahan daring dengan baik selama proses pembelajaran berlangsung.

\section{d. Inovasi Dosen dalam Pembelajaran Daring}

Agar pembelajaran bahasa Arab secara daring berlangsung tertib, menarik, dan efektif, diperlukan komitmen seorang dosen untuk disiplin masuk di awal waktu dan kompetensi seorang dosen dalam menggunakan metode pembelajaran secara bervariasi. Berdasarkan survey yang dilakukan pada mahasiswa yang belajar bahasa Arab di semester 2 pada Gambar 6, sebanyak 99 responden mengakui bahwa dosen bahasa Arab memulai perkuliahan tepat waktu, 27 responden sangat mendukung bahwa dosen memulai perkuliahan tepat waktu, dan 45 responden tidak setuju mengatakan dosen masuk tepat waktu. Ini menunjukkan bahwa dosen bahasa Arab di STAIN Mandailing Natal sebahagian besar disiplin masuk tepat waktu dalam kelas virtual.

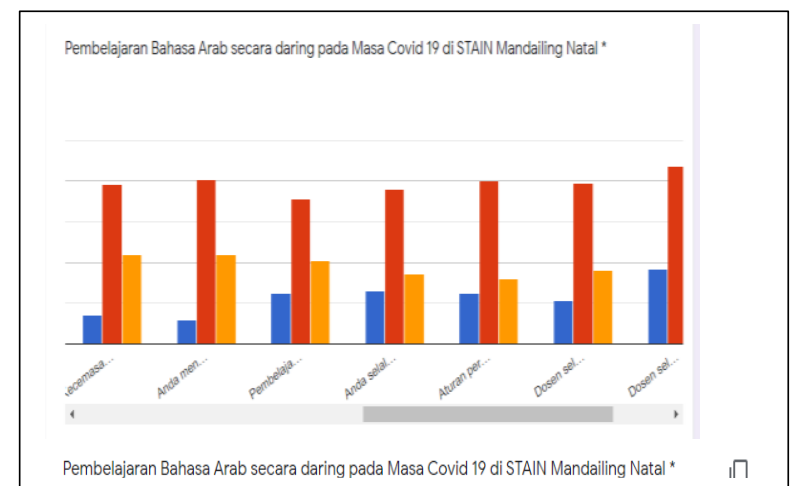

Gambar 6. Konsistensi dosen dalam pembelajaran daring

Selain disiplin waktu, dosen juga

harus selalu memberikan motivasi belajar bahasa arab kepada mahasiswa, disebabkan tidak semua mahasiswa alumni dari pesantren dan memiliki dasar bahasa Arab yang cukup. Motivasi belajar bahasa Arab penting diberikan agar mahasiswa semangat dalam belajar bahasa Arab. Dapat diketahui bahwa sebanyak 109 responden menyatakan bahwa dosen selalu memberikan motivasi belajar bahasa Arab, 46 responden sangat mendukung pernyataan ini. Sedangkan yang menyatakan dosen tidak memberikan motivasi hanya 16 orang. Ini berarti mayoritas dosen bahasa Arab di STAIN Mandailing Natal memberikan motivasi belajar bahasa Arab kepada mahasiswanya.

Dalam pembelajaran daring, dosen juga dituntut untuk dapat cepat dalam memberikan respon/ umpan balik kepada mahasiswa seperti pada perkuliahan tatap muka. Sebanyak 107 responden mengakui bahwa dosen bahasa Arab STAIN Mandailing Natal cepat tanggap memberi dan menerima respon dalam pembelajaran daring. Sebanyak 32 responden juga menguatkan pendapat ini dengan menyatakan bahwa dosen sangat responsif dalam pembelajaran daring. Hanya ada 32 responden yang menjawab tidak setuju dengan pernyataan itu. 
Dapat disimpulkan bahwa sebahagian besar dosen bahasa Arab STAIN Mandailing Natal sangat responsif dalam pembelajaran daring.

Pembelajaran yang efektif dan menarik tidak lepas dari metode dosen dalam mengajar. Semakin bervariasi metode pengajaran bahasa Arab yang digunakan, maka akan semakin menarik dan menyenangkan bagi para pembelajar. Melalui diagram pada Gambar 7. Diketahui bahwa 86,5\% dosen bahasa Arab STAIN Mandailing Natal menggunakan metode pengajaran yang bervariasi. Hanya 13,5\% yang menyatakan monoton. Ini artinya hanya sebahagian kecil responden yang menyatakan bahwa metode pengajaran yang digunakan dosen bahasa Arab tidak bervariasi atau monoton. Sebaliknya, sebahagian besar responden sepakat menyatakan bahwa metode mengajar bahasa yang digunakan di STAIN Mandailing Natal sangat bervariasi sehingga tidak membosankan.

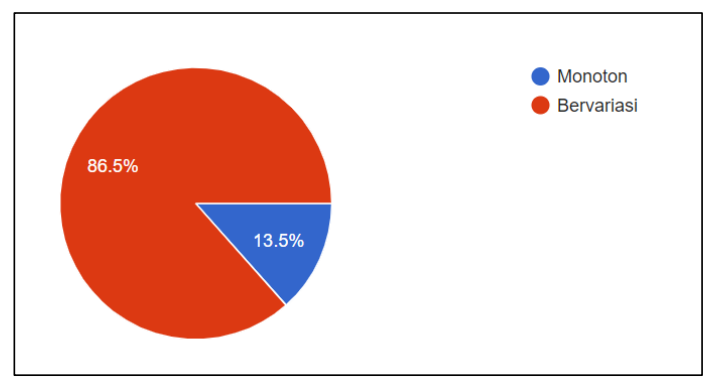

Gambar 7. Inovasi pembelajaran bahasa Arab daring

Pembelajaran daring seharusnya tidak membatasi kreatifitas dosen. Dosen bahasa Arab berinovasi menggabungkan metode yang ada, seperti metode komunikasi, metode gramatika terjemah, metode langsung, metode audiolingual, metode elektik dan qiraah, kemudian dikolaborasikan dengan media pembelajaran berbasis audio visual serta internet, seperti penggunaan pdf arabiyah baina yadaik yang dilengkapi dengan audio visualnya, film, youtobe, artikel bahasa Arab, serta penugasan berbasis produk merupakan inovasi pembelajaran yang menyenangkan dan bermanfaat bagi mahasiswa. (Syafaah, 2019)

Pembelajaran daring juga membuka peluang bagi dosen untuk memberi tugas berbasis internet kepada mahasiswa. Dosen membuka wawasan mahasiswa dan memperkaya dengan pengalaman baru melalui tugas mendownload, mereview, menganalisis sumber-sumber bahasa Arab dari internet, seperti program maktabah syamilah yang berisi kitab-kitab klasik, makalah dan hasil penelitian melalui alamat www.shamela.ws. Membaca dan merangkum kitab-kitab bahasa Arab melalui situs http:/www.scribd.com. Menulis sinopsis dan menceritakan kembali film-film kartun pendek bahasa Arab yang didownload melalui situs www.youtobe.com, mereview koran bahasa Arab melalui situs saudia online.com. Menggunakan Mu'jam internet atau global translator, serta menugaskan membaca majalah bahasa Arab yang dilihat pada situs www.wafir.com. (Azzuhri, 2009). Masih banyak lagi situs bahasa Arab yang perlu dipromosikan kepada mahasiswa untuk menambah motivasi dan antusiasme mahasiswa terhadap pembelajaran bahasa Arab. Dengan begitu, Covid-19 dan pembelajaran daring dapat membawa peningkatan inovasi bagi dosen dan mahasiswa dengan pemanfaatan teknologi dalam pembelajaran bahasa Arab.

\section{KESIMPULAN}

Berdasarkan hasil dan pembahasan penelitian, kesimpulan yang dapat ditarik yaitu sebagai berikut : 1) Inovasi pembelajaran secara daring pada mata kuliah Bahasa Arab di STAIN Mandailing Natal diaplikasilan melalui Aplikasi yang biasa digunakan dalam pembelajaran daring seperti Whatsap, Gmail, Zoom, Ed-Link, Google Meet, dan 
Siakad cukup mudah diakses oleh mahasiswa; 2) Sangat disarankan pendidik (dosen) dalam perkuliahan daring tidak hanya membagikan materi dalam bentuk pdf atau ppt, atau informasi secara teks (deskriptif). Tetapi memberikan juga tutorial dalam perkuliahan daring baik secara langsung misalkan menggunakan google classroom, aplikasi zoom / google meet. Bisa juga memberikan tutorial dalam bentuk media misal dengan membagikan link Youtube, video pembelajaran, Animasi, atau rekam layar; 3) Strategi agar pembelajaran daring berjalan sesuai dengan jadwal. Beberapa Cara yang bisa ditempuh yaitu 1) meminta kepada mahasiswa mengingatkan ketika pembelajaran akan dimulai, 2) dosen mendownload aplikasi siakad cloud sebagai pengingat dan dapat digunakan di STAIN Mandailing Natal, sehingga pembelajaran bisa dimulai kapanpun dan dimanapun. 3) Mengingat tugas perkuliahan yang harus diselesaikan oleh mahasiswa cukup banyak, perlunya ada kebijaksanaan dari dosen untuk memberikan tenggang waktu untuk pengumpulan tugas kepada mahasiswa. Sehingga dapat diketahui bahwa pembelajaran Bahasa Arab daring di STAIN Mandailing Natal pada masa Covid-19 memberi ruang inovasi bagi dosen dan mahasiswa sehingga tujuan pembelajaran bahasa Arab tercapai seperti yang diharapkan.

\section{DAFTAR PUSTAKA}

Abidah, A., Hidaayatullaah, H. N., Simamora, R. M., Fehabutar, D., \& Mutakinati, L. (2020). The Impact of Covid-19 to Indonesian Education and Its Relation to the Philosophy of "Merdeka Belajar." Studies in Philosophy of Science and Education, 1(1), 38-49. https://doi.org/10.46627/sipose.v1i 1.9 .
Anah, S. (2020). Pembelajaran Bahasa Arab Daring. Al-Fakkar: Jurnal Ilmiah Pendidikan Bahasa Arab, 1 (Februari), 92027. http://repositorio.unan.edu.ni/2986/ 1/5624.pdf.

Anggrawan, A. (2019). Analisis Deskriptif Hasil Belajar Pembelajaran Tatap Muka dan Pembelajaran Online Menurut Gaya Belajar Mahasiswa. MATRIK: Jurnal Manajemen, Teknik Informatika dan Rekayasa Komputer, 18(2), 339-346. https://doi.org/10.30812/matrik.v1 8i2.411.

Astuti, P., \& Febrian, F. (2019). Blended Learning Syarah: Bagaimana Penerapan dan Persepsi Mahasiswa. Jurnal Gantang, 4(2), 111-119.

https://doi.org/10.31629/jg.v4i2.15 60.

Azzuhri, M. (2009). Metode dan Media Pembelajaran Bahasa Arab Berbasis Internet di Era Teknologi Informasi. INSANIA : Jurnal Pemikiran Alternatif Kependidikan, 14(3), 348-445. https://doi.org/10.24090/insania.v1 4i3.360.

Batubara, H. H. (2016). Penggunaan Google Form Sebagai Alat Penilaian Kinerja Dosen Di Prodi Pgmi Uniska Muhammad Arsyad Al Banjari. Jurnal Pendidikan Dasar Islam, 8(1). https://www.google.com/intl/id/for ms/about/.

Bulan, S., \& Zainiyati, H. S. (2020). Pembelajaran Online Berbasis Media Google Formulir dalam Tanggap Work From Home Masa Pandemi Covid-19 di Madrasah Ibtidaiyah Negeri (MIN) 1 Paser. SYAMIL: Jurnal Pendidikan Agama Islam (Journal of Islamic Education), 8(1), 15-34. 
https://doi.org/10.21093/sy.v8i1.23 00 .

CNNIndonesia. (n.d.-b). 65 Kampus Kuliah dari Rumah, Sultan Yogya Ragukan Efektivitas.Retrieved from https://www.cnnindonesia.com/nas ional/20200316110707-20483756/65-kampus-kuliah-darirumah-sultan-yogya-ragukanefektivitas.

D. Jamaluddin, T. Ratnasih, et al. (2020). Pembelajaran Daring Masa Pandemik Covid-19 Pada Calon Guru.

Darmalaksana, W. (2020). WhatsApp Kuliah Mobile. 1-7.

De Giusti, A. (2020). Policy Brief: Education during COVID-19 and beyond. Revista Iberoamericana de Tecnología en Educación y Educación en Tecnología, 26, e12. https://doi.org/10.24215/18509959. 26.e12.

Dhawan, S. (2020). Online Learning: A Panacea in the Time of COVID-19 Crisis. Journal of Educational Technology Systems, 49(1), 5-22. https://doi.org/10.1177/004723952 0934018.

Dinata, K. B. (2022). Refleksi Pembelajaran Daring di Universitas Muhammadiyah Kotabumi di Masa Pandemi Covid-19. EDUKATIF: JURNAL ILMU PENDIDIKAN, 4(1), 240-249.

Firman, \& Rahman, S. R. (2020). Pembelajaran Online di Tengah Pandemi Covid-19 Firman1, Sari Rahayu Rahman1. Indonesian Journal of Educational Science (IJES), 2(2), 81-89.

Gunawan, H., (2017). Dasar-Dasar Metodologi Penelitian Pendidikan. Fakultas Tarbiyah dan Keguruan UIN Sunan Gunung Djati, Bandung.

Hamdani, A. R., \& Priatna, A. (2020).
Efektifitas Implementasi Pembelajaran Daring (Full Online) Dimasa Pandemi Covid- 19 Pada Jenjang Sekolah Dasar Di Kabupaten Subang. Didaktik: Jurnal Ilmiah PGSD STKIP Subang, 6(1), 1-9. https://doi.org/10.36989/didaktik.v 6 i1.120.

Khusniyah, N. L., \& Hakim, L. (2019). Efektivitas Pembelajaran Berbasis Daring: Sebuah Bukti Pada Pembelajaran Bahasa Inggris. Jurnal Tatsqif, 17(1), 19-33. https://doi.org/10.20414/jtq.v17i1. 667.

Kuntarto, E. (2017). Keefektifan Model Pembelajaran Daring Dalam Perkuliahan Bahasa Indonesia di Perguruan tinggi. Journal Indonesian Language Education and Literature, 3(1), 53-65. http://www.syekhnurjati.ac.id/jurn al/index.php/jeill/\%0APEMBELAJ ARAN.

Lianawati, A. (2022). Analisis Deskriptif Burnout Mahasiswa Bimbingan dan Konseling Selama Pembelajaran Daring. Edukatif: Jurnal Ilmu Pendidikan, 4(2), 1678-1685.

Novebri. (2021). Kreativitas Guru dalam Meningkatkan Kualitas Pembelajaran di SMKN 2 Pariaman. PRODU: Prokurasi Edukasi-Jurnal Manajemen Pendidikan Islam, 2(2), 147-157.

Novebri, \& Afrizal. (2021). Hubungan Strategi Pembelajaran terhadap Hasil Belajar Peserta Didik di SMP IT Al-Husnayain. Jurnal PAKAR Pendidikan, 18(2), 33-44.

Novebri, \& Dewi, S. (2020). Correlation between Students's Ability to Memorize the Qur'an and Students' Learning Achievement at Islamic Boarding Schools in Indonesia. Khalifa: Journal of Islamic 
Education, 4(2), 118-141.

Pendy, A., Suryani, L., \& Mbagho, H. M. (2022). Analisis Keefektifan Pembelajaran Online di Masa Pandemi Covid-19 pada Mahasiswa Pendidikan Matematika. Edukatif: Jurnal Ilmu Pendidikan, 4(1), 19-27.

Putria, H., Maula, L. H., \& Uswatun, D. A. (2020). Analisis Proses Pembelajaran dalam Jaringan (DARING) Masa Pandemi Covid19 Pada Guru Sekolah Dasar. Jurnal Basicedu, 4(4), 861-870. https://doi.org/10.31004/basicedu.v $4 \mathrm{i} 4.460$.

Sadikin, A., \& Hamidah, A. (2020). Pembelajaran Daring di Tengah Wabah Covid-19. Biodik, 6 (2), 109-119.

https://doi.org/10.22437/bio.v6i2.9 759.

Susanty, S. (2020). Inovasi Pembelajaran Daring Dalam Merdeka Belajar. Jurnal Ilmiah Hospitality, 9(2), 157-166. https://doi.org/10.47492/jih.v9i2.2 89.

Syafaah, D. (2019). Inovasi Pembelajaran Bahasa Arab pada Prodi Bahasa dan Sastra Arab IAIN Tulungagung dalam Menghadapi Tantangan Era Industri 4.0.
Prosiding Konferensi Nasional Bahasa Arab V, 849-859.

Wulandari, H., \& Purwanta, E. (2020). Pencapaian Perkembangan Anak Usia Dini di Taman Kanak-kanak selama Pembelajaran Daring di Masa Pandemi Covid-19. Jurnal Obsesi: Jurnal Pendidikan Anak Usia Dini, 5(1), 452. https://doi.org/10.31004/obsesi.v5i 1.626. 